\title{
MALAYSIAN JOB SHOP MANUFACTURING'S PRACTICES: CHARACTERISTICS IDENTIFICATION USING THE RASCH MEASUREMENT THEORY
}

\author{
MOHD SUHAIMI SHAMSUDDIN*1 AND MOHD SHALADDIN MUDA²
}

${ }^{I}$ Fakulti Ekonomi Pengurusan, University College Bestari, Putera Jaya, Bandar Permaisuri, 22100 Setiu, Terengganu. ${ }^{2}$ Fakulti Perniagaan, Ekonomi dan Pembangunan Sosial, Universiti Malaysia Terengganu, 21030 Kuala Nerus, Terengganu.

*Corresponding author: suhazlin@yahoo.com

Submitted final draft: 15 May $2020 \quad$ Accepted: 22 June 2020

http://doi.org/10.46754/jssm.2021.04.020

\begin{abstract}
The purpose of this study is to investigate the characteristics useful for Malaysian Job-Shop manufacturing small and mid-size enterprises SMEs to craft their "Best-Practices" using the Rasch Measurement Theory. The research aimed at answering fundamental questions that every enterprise is confronting relating to their practices that is transformed into performance. The existing data from the census sampling comprising 522 Job-Shop manufacturing SMEs, which was collected for previous research. The Rasch model, was used to summarize respondents on variables under study, involving the testing of variables and model testing. In general, the analysis results revealed that for most respondents, their desire is to ensure their processes are understandable and easy to conduct, meaning that activities, that consider employees' opinions and allow a certain degree of flexibility within the enterprise activites have a significant impact on their ability to capture a portion of the market. The result also indicates that 14 items from the 5 identified determinants were highly considered by the respondents in choosing their practice, thus, can be identified as traits or characteristics for practice adoption. The findings will be useful for the enterprises to craft their own best practices at the micro or a macro level in order to continuously improve their performance.
\end{abstract}

Keywords: Job shop manufacturing, smes, best practice, rasch measurement theory.

\section{Introduction}

Since the late 1970's and the beginning of 1980 's the term "best practice" has interested management scholars, both industrial and academic (Laugen et al., 2005; Shamsuddin et al., 2012). The term indicates leadership, management and operational approaches, that are believed to be able to allow enterprises to achieve exceptional performance levels consistently, although it is fairly subjective and might depend upon enterprise and have different meanings. Hallencreutz and Turner (2011) and AlManei et al. (2017), concluded that it is impossible to find a single generalised best practice as it is subject to the experience from a particular point of view, making a different enterprise might have experienced a different reality. Best practices, technically involve a number of critical practices ranging from human resource development and the improvement of technically competent management group to quality enhancement and investment in improving the equipment and facilities (Tuan Hassan et al., 2014; Zakaria et al., 2018). Although a significant body of research had reported a positive correlation between best practices and the performance of small and midsize enterprises (SMEs), none of which discussed the characteristics of the term (Shamsuddin et al., 2012).This impact the SMEs and making them struggle to identify the most appropriate practice for better performance.

In the Malaysian market place, SMEs continue to expand at a faster pace than the overall economy, despite the unstable and challenging environment they face. In 2016 SMECorp (2017) reported that the sector recorded a growth of $5.2 \%$ in real gross domestic product (GDP) which contributed a total of $36.6 \%$ of the country's GDP. SMEs for 
long have been assumed to play a key role in national economies around the world, generating employment, value addition and contribution to innovation (SMECorp, 2017).

Although their role is well known, they still face barriers and challenges which undermine their performance. Bourletidis and Triantafyllopoulos (2014); Tuan Hassan et al. (2014); Kohl et al. (2015); Wan Mohd Nasir et al. (2017) and Norbit et al. (December 2017) mentioned that globalisation, technological change and liberalization are the rising challenges faced by SMEs that resulted in low productivity, poor practice management, lack of management capabilities and shortage of skills in a fast changing business environment.

In order to remain competitive and innovative, SMEs will have to understand today's uncertain environment and continuously adapt to changes and respond quickly (Bahri et al., 2011; Singh \& Mahmood, 2014; Wan Mohd Nasir et al., 2017). They must understand that this uncertain and quick changing environment constitutes the main source of opportunities and at the same time influenced them with various elements such as information resources, technology development, threat-regulation and restrictions on capital and information (Hashim, 2010; Tuan Hassan et al., 2014; Shamsuddin M.S., 2018).

Constrained by a lack of adequate funding, limited skilful workforce, and leadership deficiencies; making SMEs struggle to identify the best practices, which would help them in becoming a competitive enterprise (Achanga et al., 2006; Bourletidis \& Triantafyllopoulos, 2014; Tuan Hassan et al., 2014; Norbit et al., December 2017). Hashim and Hassan (2008); AlManei et al. (2017); Wan Mohd Nasir et al. (2017); and Shamsuddin M.S. (2018) stated that issues such as late delivery, lack of product acceptance and inability to target the right market are the results of compatibility of the practice adopted within SMEs' culture and environment that making them struggle to stay competitive, due to unsuccesful implementation of the chosen practice which are not suitable for SMEs. The condition become worst when this effects employees confidence, and resulted in low commitment to the enterprise (Chong et al., 2019).

The study of the adoption of best practices within Malaysian SMEs shown a multiple determinants contribute to the adoption of such practices within this sector. As concluded by Hashim (2010); and Annuar and Mohd Yusuff (2011) there were 12 factors influencing SMEs in practice adoption typically includes;

- Employee Relationship

- Supplier Relationship

- Cost Involved

- Waste Elimination

- Competitiveness

- Quality System

- Customer Relationship

- Responsiveness

- Continuous Improvement

- Market Orientation

- Codification

- Flexibility

Shamsuddin et al., (2012), later explained that from a Job-Shop manufacturing's perspective, these 12 factors can be grouped into 5 categories namely:

- $\quad$ Requirement to Sustain (RTS)

- Superior than Competitor (STC)

- Customer Focus (CF)

- Requirement for Growth (RFG)

- Process Involved (PI)

The rest of the paper will indicate to what extent the Malaysian job-shop manufacturing SMEs established their type and context of practices used. This paper is organised as follows; next sub topic briefly explains the instrumentation involved, that discusses the questionnaire and sampling design; followed by the sub topic that discusses the analytical approach and empirical evidence and will be closed with a conclusion. 


\section{The Instrumentation}

\section{Questionnaire}

This study, is ebased on the questionnaire developed through the qualitative study conducted between March to September 2012, consists of 48 items as in Table 1. The questionnaire was developed to empirically judge the perception of the respondents about the various factors that influence their choice of practice, and to identify gaps between the current practices of enterprise and their opinion on such acts. The questionnaire was developed with the help of valuable inputs from practitioners, experts, and professionals along with the information gathered from literature.

Selected papers for review included leading journals on benchmarking, agile management, and technology management discipline, as well as cross-disciplinary papers from related fields such as operation and production management, and productivity and performance management.

Input from practitioners was gathered through a semi-structured interview and observation (the most convenient technique that allowed the researcher to unveil concealed issues (Alnaqbi, 2011; Bryman \& Bell, 2011)) at selected manufacturing job-shop enterprises. Researcher sought support from expertise and manager in order to administer them. Expertise from university entitles Associate Professor and Professor, and three managers from industrial organization were approached in order to secure the reliability of the survey questionnaires.

Table 1: Items in questionnaire

\begin{tabular}{|c|c|c|}
\hline $\begin{array}{l}\text { Entry } \\
\text { No. }\end{array}$ & Description & ID No. \\
\hline A & Factor 1 :- A: Process Involved & \\
\hline 001 & The policy requires that all activities need to be recorded & A1 \\
\hline 002 & Management takes seriously the opinion of each employee and customer. & A2 \\
\hline 003 & $\begin{array}{l}\text { The organization always tries to achieve the shortest possible throughput } \\
\text { time. }\end{array}$ & A3 \\
\hline 004 & The company has a system that allows continuous improvement. & A4 \\
\hline 005 & The flexible operating system applied is appropriate. & A5 \\
\hline 006 & All processes require a written procedure and need to be recorded & A6 \\
\hline 007 & Flexibility is one of the requirements for sustainability. & A7 \\
\hline 008 & Use of Customer Satisfaction Rate as Improvement Driver & A8 \\
\hline 009 & $\begin{array}{l}\text { Customer satisfaction survey and complaint information issued as feedback } \\
\text { for improvement }\end{array}$ & A9 \\
\hline 010 & Process flexibility plays an important role for growth & $\mathrm{A} 10$ \\
\hline 011 & $\begin{array}{l}\text { Management team understands the competition and revolutionary ideas with } \\
\text { proven performance. }\end{array}$ & A11 \\
\hline 012 & Employees received training to perform multiple tasks. & A12 \\
\hline 013 & $\begin{array}{l}\text { The company strives to ensure that employees possess different expertise/ } \\
\text { skills. }\end{array}$ & A13 \\
\hline B & Factor 2:-B: Requirement to Sustain & \\
\hline 014 & Employee Performance is always at the best & B1 \\
\hline 015 & The employee understands and is aware of the company's vision & B2 \\
\hline 016 & Product Return Rate & B3 \\
\hline
\end{tabular}




\begin{tabular}{|c|c|c|}
\hline 017 & The company can survive in crisis situations & B4 \\
\hline 018 & Communication between Employee & B5 \\
\hline 019 & The management has always acted on the vision and mission. & B6 \\
\hline 020 & Communication with Supplier will enable sustainability & B7 \\
\hline $\mathbf{C}$ & Factor 3 :-C: Superior than Competitor & \\
\hline 021 & Management team strives for elimination of waste and resource utilization. & $\mathrm{C} 1$ \\
\hline 022 & The company strives to produce the best product for its customers & $\mathrm{C} 2$ \\
\hline 023 & $\begin{array}{l}\text { Management team encourages employees to work together to achieve } \\
\text { common goals, rather than encourage competition among individuals. }\end{array}$ & $\mathrm{C} 3$ \\
\hline 024 & The cost factor is essential to be the best & $\mathrm{C} 4$ \\
\hline 025 & The customer is always right. Try to fulfil their request as much as possible. & $\mathrm{C} 5$ \\
\hline 026 & The management always makes comparisons with the best & C6 \\
\hline 027 & The system applied effectively controls the cost & $\mathrm{C} 7$ \\
\hline 028 & The company has away that allows customers to lodge complaints & $\mathrm{C} 8$ \\
\hline 029 & $\begin{array}{l}\text { Top management always ensures that the company is as competitive as } \\
\text { possible. }\end{array}$ & $\mathrm{C} 9$ \\
\hline $\mathbf{D}$ & Factor 4 :-D: Requirement for Growth & \\
\hline 030 & The documentation is clear and up-to-date & D1 \\
\hline 031 & There are staff, who supervise and record all the activities undertaken & D2 \\
\hline 032 & $\begin{array}{l}\text { There is a system to identify the resources in the project, which implemented } \\
\text { as serial numbers, nickname etc. }\end{array}$ & D3 \\
\hline 033 & Operating procedures are available in writing. & D4 \\
\hline 034 & Each operation is designed to achieve optimal utilization of resources. & D5 \\
\hline 035 & The quality policy is available in writing & D6 \\
\hline 036 & Delivery Time is the general concern & D7 \\
\hline 037 & Increasing sales turnover & D8 \\
\hline 038 & There is a system that ensures the quality of the product & D9 \\
\hline 039 & Quality of Material Supplied & D10 \\
\hline 040 & Supplier Capability & D11 \\
\hline $\mathbf{E}$ & Factor 5 :-E : Customer Focus & \\
\hline 041 & $\begin{array}{l}\text { Management team always monitors manufacturing costs, quality control cost } \\
\text { and marketing cost }\end{array}$ & E1 \\
\hline 042 & Customer Loyalty & $\mathrm{E} 2$ \\
\hline 043 & All the facilities are completely reliable & E3 \\
\hline 044 & The company is serious in addressing the issue of product quality & $\mathrm{E} 4$ \\
\hline 045 & Customers are the company's main asset & E5 \\
\hline 046 & $\begin{array}{l}\text { Each staff member always ensures that the equipment is maintained } \\
\text { according to schedule }\end{array}$ & E6 \\
\hline 047 & The reduction in manufacturing costs is appreciable & E7 \\
\hline $\mathbf{F}$ & Practice & \\
\hline 048 & The practices adopted are suitable for the company culture & F1 \\
\hline
\end{tabular}




\section{The Pilot Test}

A pilot test was conducted over the period of four months, from October 2012 to February 2013, among respondents from the target population to evaluate the questionnaire in terms of readability, understandability and accuracy of its content. To analyze the pilot test, researcher used reliability test and the results are shown in Table 2 and 3.

The questionnaire focused on identifying the most influential factors among the identified factors, namely, Process Involved (PI), Requirement to Sustain (RTS), Requirement for Growth (RFG), Superior than Competitor (STC) and Customer Focus (CF).

The survey was expected to provide an understanding of the principles from the practitioner's point of view as well as enable the identification of important factors along with other significant determinants of practice adopted. The questionnaire consisted of six sections $\mathrm{A}$ to $\mathrm{F}$ designed with statements on a 5-point Likert scale (1 equivalent to "Strongly Disagree/ Strongly Not Suitable" and 5 equivalent to "Strongly Agree/ Strongly Suitable") as per Table 1.

\section{Sampling Design}

The questionnaire was distributed among 522 identified Job-shop manufacturing SMEs in Peninsular Malaysia listed in the SME Corporation directory on the agency's website, together with the information gather from Majlis Amanah Rakyat (MARA) and Perbadanan Usahawan National Berhad (PUNB). The researcher decided to adopt census technique in this research since the total number of respondents identified were less than 600 . The survey was conducted between mid of March 2013 until the end of March 2014.

The uses of "the census" basically normal in research related to SMEs in Malaysia environment, this was due to their attitude toward research. Generally, a response rate of less than 25 percent can be achived, as example, Ahmed and Hassan, (2003) when conducting a survey and investigations on the application of quality management tools and techniques within Malaysian SMEs, received only 11.15 percent of the total 595 identified enterprises as a return rate which is far below their expectation. $\mathrm{Md}$ Deros et al., (2006) suggested that researchers should use a census technique because it's hard to identify the real number of existing SMEs due to too many agency related. This might emphasize that the 522 Job-shop type manufacturing SMEs identified in SME corporation list might be different if we using the other agency list.

Table 2: Reliability statistics

\begin{tabular}{cccc}
\hline Factor & Cronbach's Alpha & $\begin{array}{c}\text { Cronbach's Alpha Based on } \\
\text { Standardized Items }\end{array}$ & N of Items \\
\hline 1 & .782 & .782 & 13 \\
2 & .634 & .635 & 7 \\
3 & .642 & .647 & 9 \\
4 & .679 & .682 & 11 \\
5 & .632 & .639 & 7 \\
\hline
\end{tabular}

Table3: Overall reliability statistics

\begin{tabular}{rrrrr}
\hline Cronbach's Alpha & \multicolumn{2}{c}{$\begin{array}{c}\text { Cronbach's Alpha Based on Standardized } \\
\text { Items }\end{array}$} & \multicolumn{2}{c}{ N of Items } \\
\hline & .818 & & .820 & 47 \\
\hline
\end{tabular}




\section{The Analysis Approach}

\section{Introduction to Rasch Modelling and their} Implementation in the Analysis

This study, adopted elements of both a deductive approach and an inductive strategy in order to identify the practice's characteristics deem to craft the best practice using the Rasch model for measurement in their analysis.

The Rasch measurement theory (RMT) is an analysis in which the total score summarizes completing a person's standing on a variable, thus it can be taken as a criterion for the structure of the responses, rather than a mere statistical description of the responses (Andrich, 1988; Schellhorn \& Sharma, 2013; Shamsuddin M.S., 2016).

As stated by Salzberger and Sinkovics (2006), since RMT is part of the item response theory (IRT), the most important merit of the model is its specific objectivity, in which both the item and the person parameter estimate are independent of each other, making the data fit the model and provide a comparable measurement tool since its possess the data invariance property, such as the same scale.

Bond and Fox (2007), later explained that RMT is a quantitative, probabilistic measurement tool that can transform raw data into abstract, equal-interval scales and unlike traditional relational statistical analysis tools, the RMT model assumes that task performance is dependent on both the ability of the subject, and the difficulty of the task item (Maley, 2009). Indeed, the RMT with Rasch model provides the necessary objectivity for the construction of a scale that is separable from the distribution of the attribute in the persons it measures (Bond \& Fox, 2007).

RMT by right refutes the use of raw, standard, and average scores as well as percentile ranks as measurement of development for several reasons. The most prominent is the score, as it is often inappropriately referred to as nothing more than a count of the credits (Bond \& Fox, 2007; Schellhorn \& Sharma, 2013). These counts mistakenly assume that every item on the point scale is equal in value, or difficulty. Most of the time, these counts are treated as though they are equal interval units, like those on a standard metre ruler.

As for the study, which used a Likert scale, clearly, the items used are not equal in creditable value, or difficulty, thus, the standard average scores, and the corresponding percentile ranks were not applicable in the analysis (Maley, 2009).

Like other analysis the validity and reliability are the most critical part in ensuring the credibility of analysis outcomes. In RMT, the Principal Component Analysis (PCA) was performed to test the uni-dimensionality of the items in the questionnaire used in the study with the purpose of answering issues related to the validity and reliability tests. Sick (2011), viewed the PCA as an extension of Rasch fit analysis used to confirm whether the Rasch difficulty dimension, thus, the construct has adequately accounted all of the non-random variation in the data.

As the items fit the model, they support the unidimensionality of the scale, and, hence explains the goodness of content validity (Wright \& Mok, 2004; Sick, 2011). PCA refines the instrument construct by conducting the process of elimination to choose which item fits best by looking at the item quality compliance. This allows only quality items to best describe the variables being studied. PCA is suitable in this situation, since their analysis supports the researcher with the post-hoc testing, having undertaken the Rasch analysis and fitting the Rasch model requirements.

PCA consists of two major steps:- choosing the item that fits best from the Local Item Dependence (LID) requirement, as LID detected dependency between pairs of items or persons (Yen, 1993; Zenisky et al., 2003) and the quality compliance with item measures standard.

In order to apply the Rasch model to the data in this study, a suitable tool for data exploration is needed. Linacre (2009), suggested that the combination of Excel ${ }^{\circledR}$ 
and WINSTEP $\AA$ software are suitable in this situation. WINSTEP ${ }^{\circledR}$ is a well-known and highly-regarded computer software program based on Rasch model principles, whereas, Excel ${ }^{\circledR}$ is used to manipulate the data files so that each factor identified could be analysed separate of the other data, and also in meaningful combinations.

This combination produced a range of research output, which could be used to construct development graphs and common linking plots.

\section{Demographic Characteristics}

In total 270 respondents, participated in the survey, representing the management of the enterprises. Since the research targets SMEs with the Job-Shop manufacturing environment, most of the respondent involved were the manager and to some extent the owner themselves to ensure the reliability of the information gathered. This number represents 51.72 percent of the identified Job-shop manufacturing SMEs in Peninsular Malaysia. Using the "number of employees" as the tool to distinguish the status of the respondents whether small or medium size, its indicated that the majority, 93.3 percent of the respondents were small enterprises with the number of employees between 5 to 74 employees. 21.5 percent (58) of the respondents were machinery and engineering based, 16.3 percent (44) were metal based operations, 17 percent (46) were construction based, and 45.2 percent (122) performed various types of operations ranging from construction to service based on customization. In term of years of operation, 51.5 percent (139) had been in business between 6 and 10 years, 30.4 percent (82) between 11 and 15 years, 9.6 percent (26) between 16 and 20 years, 4.4 percent (12) less than 6 years in operation, 3.7 percent (10) had been in operation more than 20 years and 0.4 percent (1) respondents did not provide the information related to their years of operation.

\section{Goodness of Measure}

As mentioned, the purpose of this article was to discuss the use of RMT to identify characteristics of practice among Malaysian job-shop manufacturing SMEs. In order to select the relevant items to represent the construct, the goodness of measure was performed with the purpose of answering issues related to the validity and reliability test.

The Principal Component Analysis (PCA), Local Item Dependence (LID), and the examination of the redundancy or possibly multicollinearity through item pairs were conducted. As suggested by Yen (1993), a LID correlation value greater than $0.4(>0.4)$ indicated that only one of the items under consideration was needed for measurement based on PCA. Further justification by Tennant and Pallant (2006) on PCA, suggested that the analysis of the residuals was conducted in detecting the second factors after Rasch factor is removed due to the understanding that originally, interpretation of

Table 4: Principal Component Analysis of Standardized ResidualVariance (in Eigenvalue units)

\begin{tabular}{lccc}
\hline & \multicolumn{2}{c}{ Observed } & Modelled \\
\hline Total raw variance in observations & 71.8 & $100.0 \%$ & $100.0 \%$ \\
Raw variance explained by measures & 23.8 & $33.2 \%$ & $32.6 \%$ \\
Raw variance explained by persons & 4.2 & $5.9 \%$ & $5.8 \%$ \\
Raw variance explained by items & 19.6 & $27.3 \%$ & $26.8 \%$ \\
Raw unexplained variance (total) & 48.0 & $66.8 \%$ & $100.0 \%$ \\
Unexplained variance in 1st contrast & 5.3 & $7.3 \%$ & $11.0 \%$ \\
\hline
\end{tabular}


this was difficult as the proportion on variance attributable to the first residual factor was reported but the total variation in data was unknown.

Subsequently, Linacre (2006) incorporated the total variation into presentable and understandable reporting using Rasch Analysis. As shown in Table 4, it can be considered that the modelled variance is 32.6 percent, but with a very little discrepancy, 33.2 percent and the unexplained variance is 7.3 percent; which is almost half the acceptable limit of 15 percent. Thus, a further test needs to be done to improve the uni-dimensionality of the questionnaire.

Table 5, tabulated the results of the examination of the redundancy or possibly multi-collinearity through item pairs. It's clearly indicated that those with moderate standardized residual pairwise correlations were item 4 and 8; item 29 and 13; item 12 and 7; item 14 and 20; and item 34 and 30 . The paired items were scrutinized due to the moderate proximity of the residual correlation $>+0.4$. Therefore, items from the same domain that exhibit criteria of mean square (MNSQ) further away from 1 (the range of +0.75 to +1.3 ) and the $Z$ standard (Z-STD) ( $t$ statistics of the infit and outfit mean square residuals) further than ' 0 ' (outside the range of -2.0 to +2.0 ) are dropped, these are items marked with the ID No. A4, A13, A7, B1 and D5.

Since the concept of fit statistics in RMT is to evaluate of an individual person's response to test items to the model; Azrilah (2010); and Nazlinda, Saidfudin, Azrilah, and Zaharim (2011) suggested the test to determine the process of item elimination to be performed in order to be acceptable by checking the item's quality compliance to the Point Measure Correlation, Infit MNSQ and Outfit Z-STD as shown in Table 6.

As recommended by Linacre (2002), researchers need to detect the dissimilarity among items as it is important to identify how the respondent's pattern accurately or predictably fits the model by converting the MNSQ statistics to the normally distributed Z-STD. In this case, Azrilah (2010) suggested four criteria to check for any outliers or misfitting data, and any items under investigation that do not meet the criteria can be discarded due to a poor quality fit. These criteria are:

- Point Measure Correlation must be between the value of 0.41 to 0.84 .

- Point Measure Correlation gave a negative value (meaning that person is predicted a misfit due to careless response or guessing)

- Outfit MNSQ value between 0.51 to 1.49

- $\quad$ Oufit Z-STD value between -2 to +2

Table 6 summarized items which fall under the pattern of misfits, these items marked with the ID number; A9, F1, D8, D7, C1, A1, B2, D2, C2, D6, E7 and E5. Hence, these 12 items were discarded due to the poor quality fit. Accordingly, a total of 17 items was dropped following the PCA criteria of Residual Correlation $>0.4$, and the item misfit pattern criteria from the questionnaire in order to improve the content, and, hence, construct validity. Further checks on the content validity reaffirm the elimination of the 17 items that contributed to the reliability and validity of the questionnaire construct. 


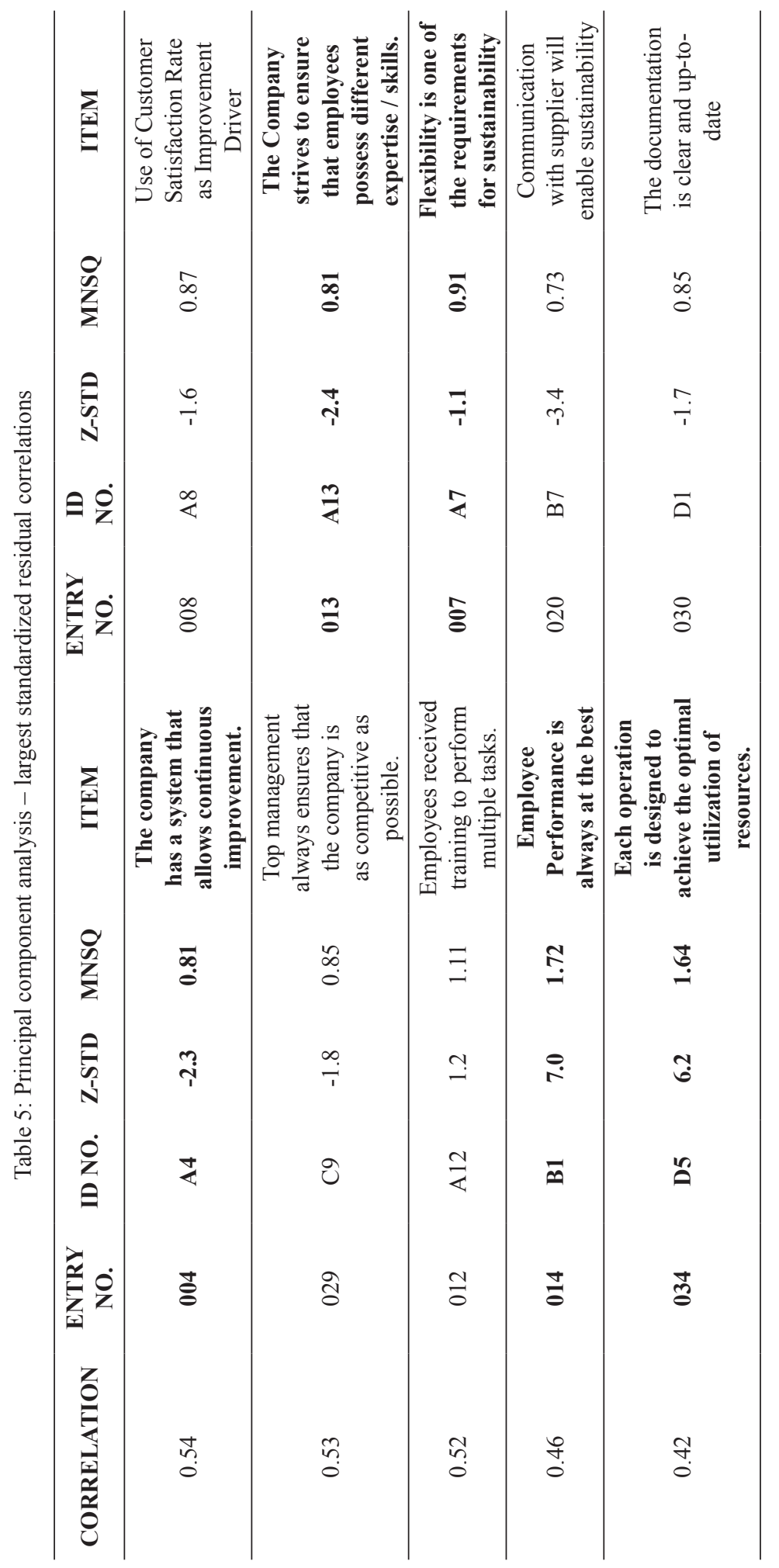




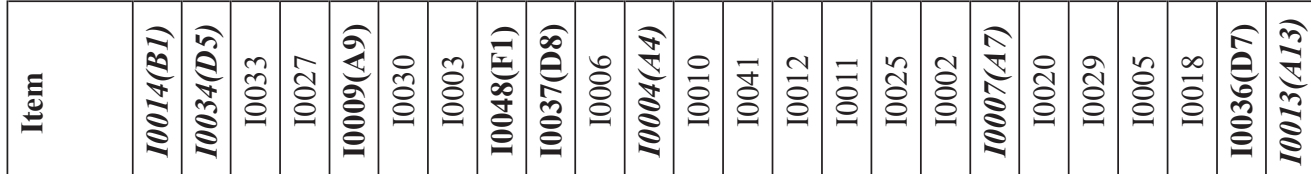

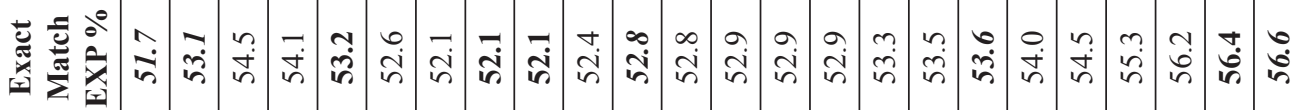

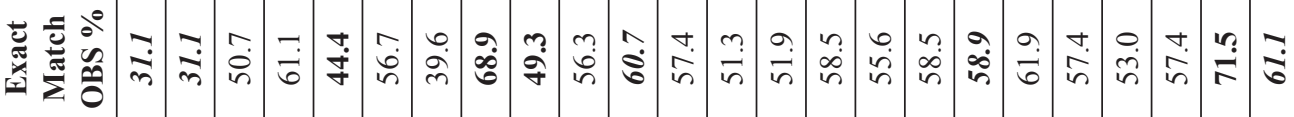

站离

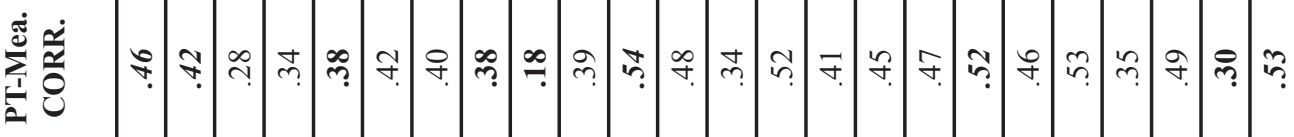

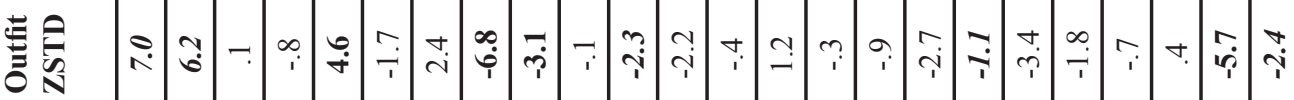

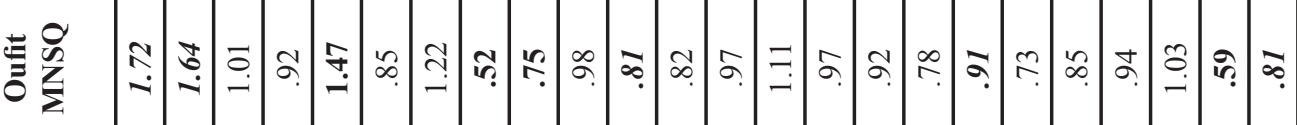

㞔

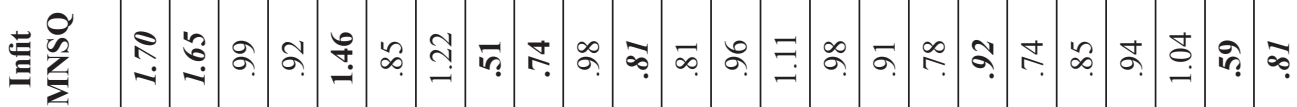

远

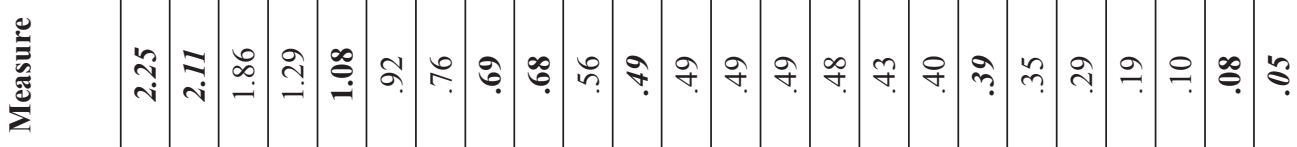

晋 考

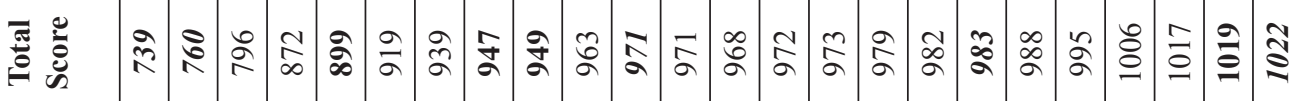

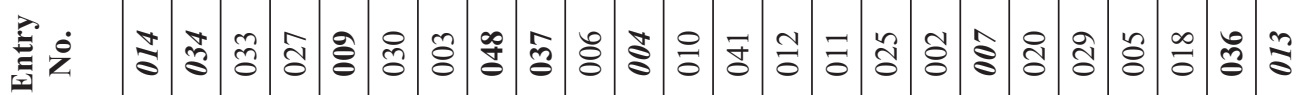




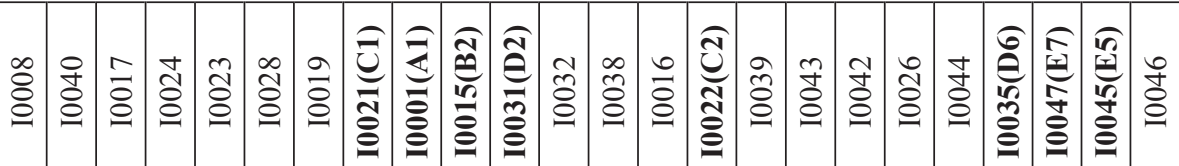

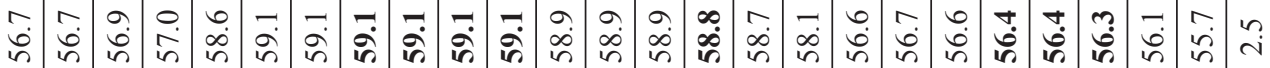

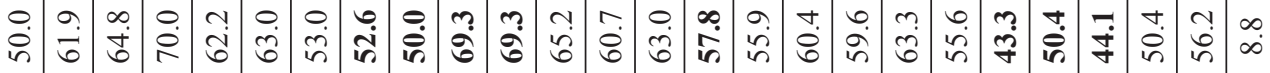

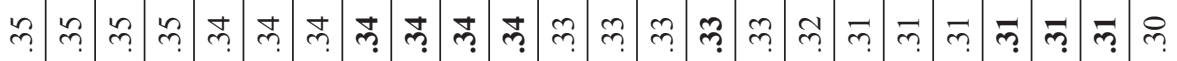

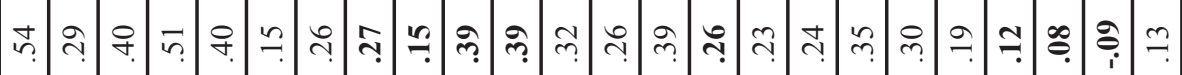

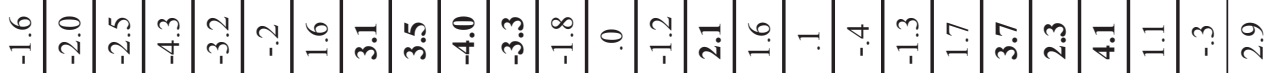

চ

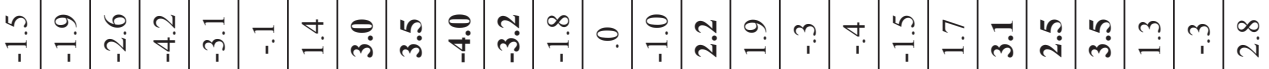

क.

g.

d.

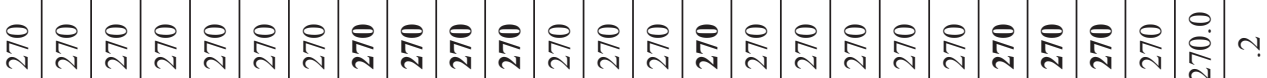

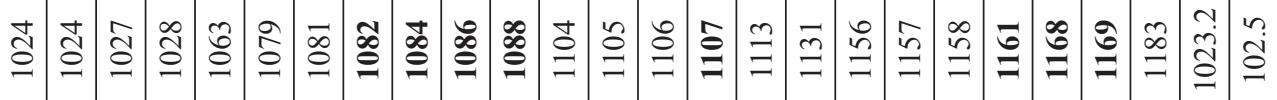

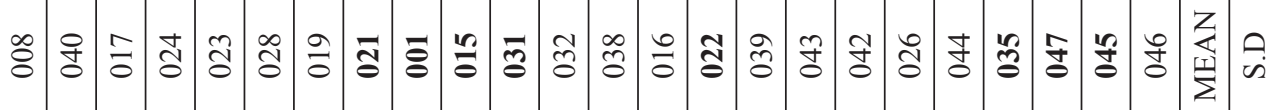




\section{Reliability and Consistency of the Measurement}

In RMT, the Cronbach's alpha coefficient method was used to estimate the reliability of the measurement (Andrich, 1988; Linacre, 2004). As according to Leedy and Ormrod (2005) and Piaw (2012), the Cronbach's alpha (KR-20) values higher than the acceptable level of 0.64 should be considered, whereas, Pallant (2010), and Sekaran and Bougie (2010), suggested that the minimum KR-20 values that could be used as an acceptable guideline should be at least 0.7 for exploratory research, 0.8 for basic research and 0.9 for a very critical issue research. For the purpose of this study, a scalar category as suggested by Fisher et al. (2010); and Jusoh et al. (n.d) was used, these scalars are as follows:

- <0.67:- poor reliability

- 0.67-0.80:- fair reliability

- 0.81-0.90:- good reliability

- 0.91-0.94:- very good reliability

- >0.94:- excellent reliability

Moreover, the reliability and consistency achieved for measures should not be taken from the KR-20 values alone, but they also need to be deliberated by the person separation index (index of internal consistency) (Andrich, 1988; Bond \& Fox, 2007; Schumacker \& Smith Jr., 2007; Linacre, 2008; Fisher et al., 2010; Pagani \& Zanarotti, 2010). Bond and Fox (2007); and Fisher et al. (2010), further suggested that the person separation index and the KR-20 value should be used to portray in the logit scale to substantiate the reliability and consistency in accordance with the RMT understanding of person's replicability and item placements, respectively.

Table 7 portrays the person reliability and KR-20 value to meet the terms of the RMT model using the summary statistic figures to answer the reliability and consistency. Its indicated that KR-20 is at 0.85 , which is considered to be acceptable reliability at the 85 percent confidence level or error free margin, and suggested that the instrument is reliable in measuring the dimension in the model.
The person reliability is given by the value of 0.84 supported by a MNSQ value of 0.99 and Z-STD value of -0.10 , which are near to 1 and 0 , respectively. The value of 0.84 here indicates that the respondents involved in the study have good replicate capabilities in answering the construct items and can be considered as reliable and consistent in answering the questionnaire.

Table 7: Person Reliability and Cronbach's Alpha

\begin{tabular}{ll}
\hline Person Reliability & $=0.84$ \\
\hline Cronbach's Alpha (KR-20) & $=0.85$ \\
\hline MNSQ & $=0.99$ \\
\hline ZSTD & $=-0.1$ \\
\hline $\begin{array}{l}\text { Summary of measurement } \\
\text { Person, N }\end{array}$ & $=270$ \\
\hline
\end{tabular}

\section{Validity and Significance of the Measurement}

Other than reliability and consistency issues, Linacre (2004), expressed concern about the content validity where the extraneous materials have been omitted, and, as a result, the test is represented by all relevant material. This was further supported by Bryman and Bell (2011), who stated that validity concerns whether or not, the set of indicators that is devised to measure a concept really measures that concept. Due to this, Andrich (1988); Bond and Fox (2007); Linacre (2008) and Jusoh et al. (n.d) suggested that in the RMT Model, the validity of the instrument construct can be better represented and understood using the proven evidence for the item reliability, that concerning the item difficulty hierarchy. For this study the item reliability index is shown in Table 8 . The value of 0.99 indicates that the items used in the study are measuring what they are designed to measure. This value also justified that the construct item is able to discriminate the respondent's ability and difficulty of tasks for the variables under study.

Table 8: Item Reliability

\begin{tabular}{ll}
\hline Item Reliability & $=0.99$ \\
\hline Summary of measured Item & $=31$ \\
\hline
\end{tabular}


As for the significance issue, the acceptable level in the RMT model is set at the 0.05 levels in which the acceptable range for the Z-STD condition is within $-2<\mathrm{Z}<+2$ in the two-tailed test (Andrich, 1988; Bond \& Fox, 2007; Linacre, 2008). Table 9 shows the analysis result, indicated that the significance value calculated by the model is equal to -0.1 , which considered as very significant in that the data fit to the model.

Table 9: Significance value

\begin{tabular}{ll}
\hline Z-Standard & $=-0.1$ \\
\hline Summary of measured Item & $=31$ \\
\hline
\end{tabular}

\section{Data and Empirical Evidence}

The RMT uses person-item map to represent the output in which both the ability/ difficulty of item estimates and their errors as well as fit indicators are represented (Bond \& Fox, 2007). The map tabulates the persons and items under study, where the items are indicated and differentiated by a unique item label, and the person is represented by the person number. In order to develop the map, the feedback from the respondents is tabulated and analysed using Winsteps ${ }^{\circledR}$ to obtain the logit values; unit measurement of item difficulty or the person's ability (Linacre, 2006).

Figure 1, shows the Wright Person-Item Distribution Map in which the person's ability and the items that are the competency attribute were plotted on the same logit scale. This map plots the distribution of the person and the item according to the respective person ability and task logit location to provide a clearer picture on the person's ability to agree and the difficulty of accepting the item.

From the figure 1, the MeanPerson is measured at 1.52 logit and the MeanItem is set at 0.00 logit. As perceived by the RMT's understanding (Azrilah et al. 2008), the level of person's ability measure is indicated by the separation of item against the person's location on the person-item map; further measures on the separation means the person is more likely to be able to respond correctly to the particular items. Similar to the item difficulty, the degree of item difficulty is replicated by the extent that the item is separated over the scale; the higher the location of the items from the item mean is considered as being more difficult compared to an item located at a lower location.

Due to this, the MeanItem is always located at 0.00 logit where the threshold is set on the logit scale and the MeanPerson is observed at 1.52 logit.

From the figure 1, it is clear that 100 percent of the respondents are above the MeanItem, indicating, that in general the respondent's ability is above the average of item difficulty. The most difficult item is "D4: Operating procedures are available in writing", which is located at 1.86 logit. This is understood, as the item asked is unfavourable by 73.38 percent (113 out of 154 respondents) and the respective respondents find it hard to accomplish.

Whereas, all the items located below the MeanItem of 0.00 logit are considered common and easily achievable for all the respondents. From the person point of view, it shows that the PersonMax is equal to 3.90 logit and the PersonMin is equal to 0.19 logit with the spread value between both at 3.71 logit and the standard deviation 0.68 . The difference between ItemMax 1.86 logit and ItemMin -1.50 logit yields a gap of 3.36 over a standard deviation of 0.79 . This shows that the spread of items ratio of 3.36/3.71 is much the same as the spread of the persons.

The map reveals that those items that fall below the PersonMin or above the PersonMax are off target items from the RMT's understanding. Those items below the PersonMin of 0.19 logit are deemed to be extremely easy items (common practice) whilst those above PersonMax of 3.90 logit are items considered to be extremely difficult to practice.

There are 12 items or 38.71 percent out of 31 items are located below the MeanItem, which are understood to be the items that are easily achievable for the respondents. The easily achievable tasks are listed in Table 10. 
Apart from the easy items, there are items that fall above the MeanItem and are considered as achievable items according to the respondent's level of achievement. There are 19 items or 61.29 percent out 31 items that fall under this category.
The list of items are as shown in Table 11. The status as "achievable items" indicates that among respondents these items seem to be applicable and implemented in their enterprises and were the major concern for them in choosing the practices.

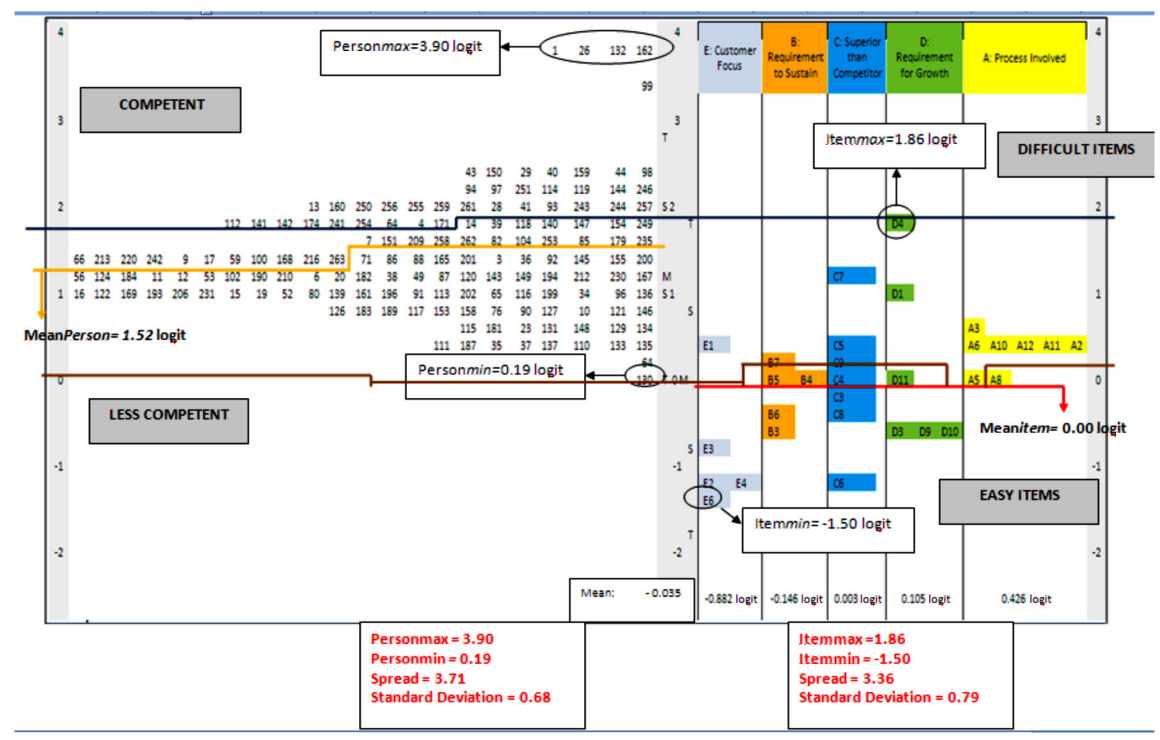

Figure 1: The Wright Person - Item distribution map

Table 10: Easily Achievable Items

\begin{tabular}{|c|c|c|}
\hline Items & Construct & Logit \\
\hline E6 & $\begin{array}{l}\text { Each staff member always ensures that the equipment is maintained according to } \\
\text { the schedule. }\end{array}$ & -1.50 \\
\hline E4 & $\begin{array}{l}\text { The company takes all complaints from the customer seriously and tries to solve } \\
\text { them as soon as possible }\end{array}$ & -1.23 \\
\hline C6 & The management always makes comparisons with the best. & -1.22 \\
\hline E2 & Customer Loyalty is at the highest & -1.21 \\
\hline E3 & All the facilities are completely reliable. & -0.96 \\
\hline D10 & Quality of materials supplied is always observed & -0.78 \\
\hline D9 & There is a system that ensures the quality of the product. & -0.71 \\
\hline B3 & Product Return Rate is capped at the lowest & -0.71 \\
\hline D3 & $\begin{array}{l}\text { There is a system to identify resources in the project implemented as serial } \\
\text { numbers, nickname etc. }\end{array}$ & -0.70 \\
\hline B6 & The management has always acted on the vision and mission. & -0.48 \\
\hline $\mathrm{C} 8$ & The company has a way that allows customers to lodge complaints. & -0.46 \\
\hline $\mathrm{C} 3$ & $\begin{array}{l}\text { Management team encourages employees to work together to achieve common } \\
\text { goals, rather than encourage competition among individuals. }\end{array}$ & -0.31 \\
\hline 12 Items & & \\
\hline
\end{tabular}


Table 11: Achievable Items

\begin{tabular}{clc}
\hline Items & \multicolumn{1}{c}{ Construct } & Logit \\
\hline D4 & Operating procedures are available in writing & 1.86 \\
C7 & The system applied effectively controls the cost & 1.29 \\
D1 & The documentations is clear and up-to-date & 0.92 \\
A3 & The organization always tries to achieve the shortest possible throughput time. & 0.76 \\
A6 & All processes require a written procedure and need to be recorded & 0.56 \\
A10 & Process flexibility plays an important role for growth & 0.49 \\
A12 & Employees received training to perform multiple tasks & 0.49 \\
E1 & $\begin{array}{l}\text { Management team always monitors manufacturing costs, quality control cost, } \\
\text { and marketing cost. }\end{array}$ & 0.49 \\
A11 & $\begin{array}{l}\text { Management team understands the competition and revolutionary ideas with } \\
\text { proven performance }\end{array}$ & 0.48 \\
C5 & The customer is always right. (Tries to fulfil as much as possible their requests) & 0.43 \\
A2 & Management takes seriously the opinion of each employee and customer & 0.40 \\
B7 & Communication with Supplier will enable sustainability & 0.35 \\
C9 & Top management always ensures that companies are as competitive as possible. & 0.29 \\
A5 & Flexible operating system applied is appropriate & 0.19 \\
B5 & Communication between Employees is at the best & 0.10 \\
\hline C4 & Employees are aware and understand the applicable system & 0.04 \\
\hline & Uses of Customer Satisfaction Rate as Improvement Driver & 0.04 \\
\hline
\end{tabular}

19 Items

The Wright Person-Item Distribution Map in Figure 1, clearly indicates that there are three characteristics that job-shop type SMEs in Malaysia should focus on when considering their practices, Process Involved $(0.426$ logit), followed by Requirement for Growth (0.105 logit), and Superior than Competitor (0.003 logit). The other two characteristics,
Requirement to Sustain (- 0.146 logit) and Customer Focus (- 0.882 logit) are considered to be the common characteristics that all companies do and consider when choosing their practices.

The logit scale enables researchers to identify the most influential items that lead the respondents to choose their practices, Figure 
1, clearly indicates that eight (8) items from Process Involved (PI), seven (7) items from Superior than Competitors (STC), six (6) items from Requirements to Sustain (RTS) and five (5) items from Requirement for Growth (RFG) and Customer Focus (CF) fit the model.

As indicated in Table 12, there are 14 items which fit the model above the Personmin score of 0.19 logit. It also clearly indicates that 87.5 percent items under PI ( 7 out of 8), 60 percent items under STC (3 out of 5), 33.3 percent items under RTS ( 2 out of 6 ), 20 percent items under RFG ( 1 out of 5 ) and $14.3 \%$ items under CF (1 out of 7) are above the Personmin score of 0.19. The results obviously indicate that among the respondents, when choosing practices, they will consider these 14 items from the 5 determinants identified, thus, suggesting that among the respondents rigid practices are not sufficient.

Table 12: Items which fit the Model and above the Personmin score of 0.19

\begin{tabular}{|c|c|c|c|c|c|}
\hline Bill & Item & $\begin{array}{l}\text { Item in } \\
\text { Survey }\end{array}$ & $\begin{array}{l}\text { Logit } \\
\text { score }\end{array}$ & Question & Factor \\
\hline 1 & 33 & D4 & 1.86 & Operating procedures are available in writing & RTS \\
\hline 2 & 27 & $\mathrm{C} 7$ & 1.29 & The system applied effectively controls the cost & STC \\
\hline 3 & 30 & D1 & 0.92 & The documentation is clear and up-to-date & RTS \\
\hline 4 & 3 & $\mathrm{~A} 3$ & 0.76 & $\begin{array}{l}\text { The organization always tries to achieve the } \\
\text { shortest possible throughput time. }\end{array}$ & PI \\
\hline 5 & 6 & A6 & 0.56 & $\begin{array}{l}\text { All processes require written procedure and need to } \\
\text { be recorded }\end{array}$ & PI \\
\hline 6 & 10 & A 10 & 0.49 & $\begin{array}{l}\text { Process flexibility plays an important role for } \\
\text { growth }\end{array}$ & PI \\
\hline 7 & 12 & A12 & 0.49 & $\begin{array}{l}\text { Employees receive training to perform multiple } \\
\text { tasks }\end{array}$ & PI \\
\hline 8 & 41 & E1 & 0.49 & $\begin{array}{l}\text { Management team always monitors manufacturing } \\
\text { costs, quality control cost, and marketing cost. }\end{array}$ & $\mathrm{CF}$ \\
\hline 9 & 11 & A11 & 0.48 & $\begin{array}{l}\text { Management team understands the competition and } \\
\text { revolutionary ideas with proven performance }\end{array}$ & PI \\
\hline 10 & 25 & $\mathrm{C} 5$ & 0.43 & $\begin{array}{l}\text { The customer is always right. (Tries to fulfil as } \\
\text { much as possible their requests) }\end{array}$ & STC \\
\hline 11 & 2 & A2 & 0.40 & $\begin{array}{l}\text { Management takes seriously the opinion of each } \\
\text { employee and customer }\end{array}$ & PI \\
\hline 12 & 20 & B7 & 0.35 & $\begin{array}{l}\text { Communication with Supplier will enable } \\
\text { sustainability }\end{array}$ & RFG \\
\hline 13 & 29 & C9 & 0.29 & $\begin{array}{l}\text { Top management always ensures that the company } \\
\text { is as competitive as possible. }\end{array}$ & STC \\
\hline 14 & 5 & A5 & 0.19 & Flexible operating system applied is appropriate & PI \\
\hline
\end{tabular}




\section{Conclusion}

The objective of the study was to prescribe the characteristics of best practices given by the respondents in order to determine the principles needed to develop these so-called "best practices", according to the respondent's perspective. The collected data were tested using the Person-Item Map and the Goodness of Fit test from RMT to check the reliability, consistency and validity of the outcome.

The results of the study suggest that, in general, respondents agree on the soundness of best practices' determinants identified from the research. The desire of most respondents is to ensure their processes are easy to understand and carry out by their respective employees. They also desire systems that enable them to grow by providing their customers with a quality deliverables.

The impression created is that, in general, the respondents consider the factors related to the process when adopting practices within their enterprises. They believe activities, such as minimising throughput time, recording all the procedures involved, providing adequate training to employees, understanding their competitive environment, considering employees' opinions and applying flexibility within enterprises have a significant impact on their ability to capture a significant portion of the market.

This finding was also supported by Ahmad and Mohamed Zabri (2016); and Wan Mohd Nasir et al. (2017) who stated that SMEs must adopt a flexible and varied mix of practices to their needs and the external conditions in which they compete.

The respondents agree with the levels of availability in the written and applied operation procedure system, which can effectively control the related costs within their respective enterprises. They stress that, their enterprises must achieve the shortest possible throughput time, recording all process involved, increase process flexibility, and focus more on training their employees, all of which is in line with the findings of the study by Zakaria et al. (2018).
The results also reflected the respondents' level of effort to up-date their documentation to ensure their growth in the market place. It also reflects the ambivalence to fulfilling customer needs, and at the same time, controlling the production costs.

The study reinforces the previous findings, in which the five identified determinants; PI, RFG, STC, RTS and CF; play a significant role in the adoption of practices among the respondents.

As indicated by the results, PI can be considered as the major determinant for the respondents in choosing their practice. Apart from that, the results also indicated that there are 14 items such as "operating procedures are available in writing"; "the documentation is clear and up-to-date"; "management team understands the competition and revolutionary ideas with proven performance"; and "management taken seriously the opinion of each employee and customer" are deemed to be important items for the respondents in their choice of practices within their operation.

\section{Acknowledgements}

My sincere gratitude and appreciation to Professor Dr. Mohd Shaladdin bin Muda, Associate Professor Ismail bin Omar and Dr. Muhammad Shahar bin Jusoh for their contributions, support and invaluable guidance and assistance. This article is part of a thesis which was submitted as partial fulfilment to meet requirements for the degree of Doctor of Philosophy at Universiti Malaysia Terengganu.

\section{References}

Achanga, P., Shehab, E., Roy, R., \& Nelder, G. (2006). Critical succes factors for lean implementation within SMEs. Journal of Manufacturing Technology Management, 17(4), 460-471.

Ahmad, K., \& Mohamed Zabri, S. (2016). The application of non-financial performance measurement in Malaysian manufacturing 
firms. Procedia Economics and Finance, 35, 476-484.

Ahmed, S., \& Hassan, M. (2003). Survey and case investigations on application of quality mangement tools and techniques in SMIs. International Journal of Quality \& Reliability Management, 20(7), 795-826.

AlManei, M., Salonitis, K., \& Xu, Y. (2017). Lean implementation frameworks: The challenges for SMEs. The 50th CIRP Conference on Manufacturing Systems (pp. 750-755). Cranfield, UK: ELSEVIER; ScienceDirect.

Alnaqbi, W. (2011). The relationship between human resource practices and employee retention in public organisations: An exploratory study conducted in the United Arab Emirates. [Thesis for the degree of Doctor of Philosophy, Edith Cowan University].

Andrich, D. (1988). Rasch Models for measurement. Newbury Park, CA: SAGE.

Annuar, A., \& Mohd Yusuff, R. (2011). Manufacturing best practices in Malaysian small and medium enterprises (SMEs). Benchmarking; An International Journal, 18(3), 331-341.

Azrilah, A. (2010). Rasch Model fundamentals: Scale coinstruct and measurement structure. Kuala Lumpur: Perpustakaan Negara Malaysia.

Azrilah, A., Noor Habibah, A., Sohaimi, Z., Azami, Z., Hamzah, A., \& Saidfudin, M. (2008). Application of Rasch Model in validating the construct of measurement instrument. International Journal of Education and Information Technology, 2(2), 105-112.

Bahri, M., St. Pierre, J., \& Sakka, O. (2011). Economic value added: A useful tool for SME performance management. International Journal of Productivity and Performance Management, 60(6), 603-621.

Bond, T. G., \& Fox, C. M. (2007). Applying the Rasch Model: Fundamental measurement in the human sciences (2nd ed). Mahwah, New Jersey: Lawrence Erlbaum Associates.
Bourletidis, K., \& Triantafyllopoulos, Y. (2014). SMEs survival in time of crisis: Strategies, tactics and commercial success stories. Procedia-Social and Behavioral Sciences, 148, 639-644.

Bryman, A., \& Bell, E. (2011). Business research methods (3rd ed.). New York: Oxford University Press.

Chong, P. L., Ong, T. S., Abdullah, A., \& Choo, W. C. (2019). Internationalisation and innovation on Balance Scorecard (BSC) among Malaysian Small and Medium Enterprises (SMEs). Management Science Letters, 9, 1617-1632.

Fisher, J., Elbaum, B., \& Coulter, A. (2010). Reliability, precision, and measurement in the contect of data ability test, survey and assessments. Journal of Physics: Conference Series, 238, 012036.

Hallencreutz, J., \& Turner, D. M. (2011). Exploring organizational change best practice: Are there any clear cut models and definitions? International Journal of Quality and Services Sciences, 3(1), 60-68.

Hashim, M. K. (January-June, 2010). Revisiting the role of small and medium sized enterprises in the Malaysian economy. Retrieved Monday July, 2011, from The Journal of The Malaysian Institute of Management;: http:// resources.miim.edu.my/mmr/2010/100102. htm.

Hashim, M. K., \& Hassan, R. (2008). Internationalisation of SMEs: Options, incentive, problems, and business strategy. Universiti Utara Malaysia Press.

Jusoh, M., Yusof, R., Abas, Z., Fakurazi, N., Abdul Aziz, A., \& Saidfudin, M. (n.d.). Reliability, consistence, validity and significance issues in Rasch Measurement Model: Quality management and cost of quality perspectives.

Kohl, H., Orth, R., Riebarthsch, O., Galeitzke, M., \& Cap, J. (2015). Support of innovation network in manufacturing industries through identification of sustainable collab- 
oration potential and best-practice transfer. Procedia CIRP 26 (pp. 185-189). CIRP.

Laugen, B. T., Acur, N., Boer, H., \& Frick, J. (2005). Best manufacturing practices: What is the best-performing companies do? International Journal of Operation \& Production Management, 25(2), 131-150.

Leedy, P., \& Ormrod, J. (2005). Practical research: Planning and design (8th ed.). New Jersey: Prentice Hall.

Linacre, J. (2002). What do infit and outfit, mean-square and standardized mean? Rasch Measurement Transactions, 16(2), 878-879.

Linacre, J. (2004). Winsteps: Multiple choice rating scale and partial credit Rasch analysis (computer program). Chicago: MESA Press.

Linacre, J. (2006). A user's guide to WINSTEPS (R) MINISTEP. Rasch-Model Computer Program; Program Manual 3.68.0. www. winsteps.com

Linacre, J. (2008). The expected value of a pointbiserial (or similar) correlation. Rasch Measurement Transactions, 22(1), 1154.

Linacre, J. (2009). WINSTEPS Version 3.68.1 [computer software]. Chicago, IL. http:// www.winsteps.com.

Maley, C. (2009). Young children's human figure drawings: An investigation using the Goodnenough-Harris Drawing Test and the Rasch Model for measurement. [PhD Thesis, James Cook University].

Md Deros, B., Mohd Yusof, S., \& Md Salleh, A. (2006). A benchmarking implementation framework for automotive manufacturing SMEs. Benchmarking: An International Journal, 13(4), 396-430.

Nazlinda, A., Saidfudin, M., Azrilah, A., \& Zaharim, A. (2011). Investigation of parallel resistive circuit PCCUT-40: Instrument construct validity to assess engineering student's understanding in electricity. Proceedings of the 10th WSEAS International
Conference on Education and Educational Technology (EDU'11)3-5 )ctober 2011. Penang.

Norbit, N., Nawawi, A., \& Azlin Puteh Salin, A. (December 2017). Corporate social responsibility practices among the SMEs in Malaysia - A preliminary analysis. Management \& Accounting Review, 16(2), 17-39.

Pagani, L., \& Zanarotti, M. (2010). Soime uses of Rasch Models parameter in customer satisfaction data analysis. Quality Technology \& Quantitative Management, 7(1), 83-95.

Pallant, J. (2010). SPSS survival manual (4th ed.). Berkshire: McGraw-Hill.

Piaw, C. Y. (2012). Asas statistik penyelidikan. Malaysia: McGraw-Hill.

Salzberger, T., \& Sinkovics, R. (2006). Reconsidering the problem of data equivalence in International Marketing Research: Contrasting approaches base on CFA and the RASCH Model for measurement. International Marketing Review, 23(4), 390-417.

Schellhorn, C., \& Sharma, R. (2013). Using the RASCH Model to rank firms by managerial ability. Managerial Finance, 39(3), 306319.

Schumacker, R., \& Smith Jr., E. (2007). Reliability-A Rasch perspective . Educational and Psychological Measurement, 67(3), 394-409.

Sekaran, U., \& Bougie, R. (2010). Research methods for business; A skill building approach. Chichester: John Wiley and Sons, Ltd.

Shamsuddin, M. (January, 2016). A study of best practice principles among job-shop manufacturing SMEs in Malaysia. [Ph.D Thesis]. Kuala Terengganu, Terengganu, Malaysia: Universiti Malaysia Terengganu.

Shamsuddin, M. (2018). Crafting the best practice among Malaysian job-shop manufacturing SMEs: Critical factors for practice implementation. International Journal of Business, Economics and Law, 15. 
Shamsuddin, N., Muda, M. S., \& Omar, I. (2012). Crafting the best practices within Malaysian job-shop type manufacturing SMEs. International Journal of Business, Economics and Law, 1, 27-33.

Sick, J. (2011). Rasch measurement and factor analysis. SHIKEN: JALT Testing \& Evaluation SIG Newsletter, 15(1).

Singh, H., \& Mahmood, R. (2014). Aligning manufacturing strategy to export performance of manufacturing small and medium enterprises in Malaysia. Social and Behavioral Sciences, 130, 85-95.

SMECorp. (2017). SME Annual Report 2016/17. Kuala Lumpur: SMECorp.

Tennant, A., \& Pallant, J. (2006). Unidimensionality matters (A tale of two Smiths?). Rasch Measuremet Transaction, 20(1) Summer, 1048-1051.

Tuan Hassan, T., Yaacob, M., \& Abdul Latif, N. (2014). Sustaining SMEs Wppd-based product manufacturing through best practices-The case of indigenous entrepreneurs in Kelantan. Social and Behaviour Sciences, 115, 221-234.
Wan Mohd Nasir, W., Al Mamun, A., \& Breen, J. (2017). Strategic orientation and performance of SMES in Malaysia. SAGE Open, $1-13$.

Wright, B. D., \& Mok, M. M. (2004). Introduction to Rasch measurement: Theory, models and application. In E. V. Smith, \& R. M. Smith, An overview of the family of Rasch measurement models (pp. 1-24). Maple Grove: JAM Press.

Yen, W. (1993). Scaling performance strategies for managing local item dependence. Journal of Education Measurement, 30(3), Performance Assessment, 187-213.

Zakaria, N., Ishak, K. A., Arshad, D., Chew Abdullah, N., \& Ahmad, N. (2018). Measuring the dimensionality of human resource management: The perspective of Malaysian SME owner managers. Management Science Letters, 8, 317-326.

Zenisky, A., Hambelton, R., \& Sireci, S. (2003). Effect of Local Item Dependence on the Validy of IRT Item, Test and Ability Statistics. Retrieved 21 December, 2017, from http://www.aamc.org: /students/mcat/research/monograph5.pdf 